\title{
A nurse led home management training programme reduced readmissions to the hospital in children with acute asthma
}

\author{
Madge P, McColl J, Paton J. Impact of a nurse-led home management training programme in children admitted to hospital with \\ acute asthma: a randomised controlled study. Thorax 1997 Mar;52:223-8.
}

\section{Objective}

To determine whether a nurse led education home management training programme for parents of children in hospital with asthma reduces readmissions.

\section{Design}

Randomised controlled trial.

\section{Setting}

4 wards of a large children's teaching hospital in Scotland.

\section{Patients}

201 children who were $>2$ years of age $(49 \%$ were from $2-5 \mathrm{y}$, $62 \%$ boys) and in the hospital with acute asthma.

\section{Intervention}

96 children were allocated to the nurse led training programme and 105 to usual care. The study nurse, who had specialist asthma training, briefly met with parents within 24 hours of admission and then, on average, held 2 further teaching and discussion sessions with each family (total approximately 45 minutes). Parents received information on asthma and its triggers; treatment and signs of impending asthma attacks; an individualised written treatment plan; a course of oral steroids with instructions about when to start; an appointment in a nurse run asthma clinic 2-3 weeks after discharge; the opportunity to contact a nurse by telephone for advice; and, if their child was $>5$ years old, a peak flow meter with instructions on its use. The investigators did not document the community follow up care in either group, nor did they ascertain steroid use in either group after discharge.

\section{Main outcome measures}

The primary outcome was hospital readmissions and the secondary outcome was number of emergency department visits.

\section{Main results}

Fewer children who received the nurse led education programme were readmitted to the hospital than were children who received usual care $(p=0.002)$ (table). The groups did not differ for emergency department visits $(7.3 \% v 6.7 \%, 95 \%$ CI for the $0.6 \%$ difference $-9 \%$ to $7 \%$ ).

\section{Conclusion}

A nurse led home management training programme delivered to parents of children in hospital with acute asthma led to fewer readmissions compared with children who received the hospital's usual discharge advice.

Nurse led home management education v usual care*

\begin{tabular}{llllll}
\hline $\begin{array}{l}\text { Outcome up } \\
\text { to 14 months }\end{array}$ & $\begin{array}{l}\text { Education } \\
\text { EER }\end{array}$ & $\begin{array}{l}\text { Usual Care } \\
\text { CER }\end{array}$ & $\begin{array}{l}\text { RRR } \\
(95 \% \text { CI })\end{array}$ & $\begin{array}{l}\text { ARR } \\
|E E R-C E R|\end{array}$ & $\begin{array}{l}\text { NNT } \\
\text { (CI) }\end{array}$ \\
\hline Readmission & $8.3 \%$ & $25 \%$ & $\begin{array}{l}67 \% \\
(31 \text { to } 84)\end{array}$ & $16 \%$ & $\begin{array}{l}7 \\
(4 \text { to } 16)\end{array}$ \\
\hline
\end{tabular}

*Abbreviations defined in glossary; RRR, ARR, NNT, and CI calculated from data in article.

Source of funding: not stated.

For article reprint: Dr J Y Paton, Department of Child Health, Royal Hospital for Sick Children, Yorkhill National Health Service Trust, Glasgow G3 8SJ, Scotland. Fax +44 (0)141 2010837.

Adapted from an abstract published in Evidence-Based Medicine 1997 Sep-Oct;2:139.

\section{Commentary}

Repeated emergency attendances and readmission to hospital might be reduced by better planned management of childhood asthma. This promising area for nursing interventions is supported by limited evidence that shows that emergency attendances and hospital readmissions can be reduced by an asthma outreach programme. ${ }^{1}$ In the UK, a nurse led clinic, which delivered an education programme that focused on symptoms and clear protocols for treatment of children by their parents, reduced symptoms and improved peak flow measurement in a trial of 91 children with asthma. $^{2}$ Further evidence is required, however, about the effects of education and nursing follow up on subsequent use of health services. This study by Madge $e t$ al reports a methodologically sound trial of a hospital based home management training programme. One nurse provided discharge education, and follow up and telephone support after discharge to parents of children who were in the hospital with acute asthma. Because the purpose of the study was to "address deficiencies in discharge care", the control group received limited advice on discharge. It is not possible to distinguish between the effects of the training programme and subsequent support after discharge.

Because the follow up period varied from 2-14 months, the duration of the effect of the nursing intervention cannot be assessed. This study shows that it is possible for a programme of nurse led home management education and follow up support to reduce readmissions for children in hospital with asthma.

$$
\begin{array}{r}
\text { Peter Callery, PhD } \\
\text { Lecturer in Nursing, } \\
\text { School of Nursing, Midwifery and } \\
\text { Health Visiting } \\
\text { University of Manchester } \\
\text { Manchester, UK }
\end{array}
$$

1 Greineder DK, Loane KC, Parks P. Reduction in resource utilization by an asthma outreach program. Arch

2 Charlton I, Antoniou AG, Atkinson J, et al. Asthma at the interface: bridging the gap between general practice and a district general hospital. Arch Dis Child 1994;70:313-8. 